\title{
A "VERDADE", ENQUANTO RELAÇÃO, A PARTIR DA QUESTÃO 16 DA PRIMEIRA PARTE DA SUMA TEOLÓGICA DE TOMÁS DE AQUINO
}

\author{
The "truth", as a relationship, from the sixteenth issue of the First Part of the Summa \\ Theologica of Thomas Aquinas \\ Paulo Adriano do Amaral Fernandes*
}

Resumo: Nosso trabalho pretende demonstrar a necessidade em ater-se, ao aspecto ou à dimensão da relação, no conceito tomásico de "verdade", para isso apresentamos uma aproximação reflexiva da Questão 16, da Primeira Parte da Suma Teológica de Santo Tomás de Aquino e propomos uma compreensão da verdade, enquanto relação. A pertinência do tema se dá a partir do problema que classicamente se enfrenta na filosofia e outras ciências, a verdade, meta do conhecimento humano, está no ser humano, sujeito racional cognoscente ou no objeto que o ser humano pretende conhecer. Na história da filosofia são conhecidas algumas posturas, uma defensora da verdade enquanto presente no intelecto humano, outra presente no objeto a ser conhecido, de um lado, um subjetivismo racionalista, de outro um objetivismo empirista, parece-nos que, mesmo havendo algumas tentativas em avançar diante destas posições extremas, não emergiram com força e temos uma visão de mundo ora cerceada pelo império da razão subjetivista, ora pela ditatura do objetivismo empirista. Esse dilema parece-nos provocador de extremismos, ceticismo e, sobretudo relativismo. A Questão 16, da Primeira Parte da Suma Teológica, está inserida, no que chamamos Tratado sobre Deus, e nesse trabalho buscamos explorar o artigo primeiro, em que Tomás discute se a verdade está apenas no intelecto, e o artigo sexto, em que se pergunta se todas as coisas são verdadeiras em razão de uma única verdade, ou de muitas. Diante das discussões provocadas no texto tomásico e de nossas considerações, propomos que um entendimento melhor da verdade se dá, na medida em que demonstramos um novo paradigma e esse é o paradigma da relação, por isso acreditamos ser importante, tanto para a gnosiologia, quanto para a antropologia, compreender a verdade, enquanto relação.

Palavras-chave: Verdade. Relação. Tomás de Aquino. Suma Teológica.
Abstract: Our work aims to demonstrate the need to abide by the aspect ratio or size tomásico the concept of "truth", for it presents a reflective approach of sixteen Issue First Part of the Summa Theologica of St. Thomas Aquinas and propose an understanding of Indeed, while relationship. The relevance of the topic starts from the problem classically faces in philosophy and other sciences, the true goal of human knowledge, is the human being, rational knowing subject or object that human beings want to know. In the history of philosophy are known some positions, while a champion of truth present in the human intellect, in this other object to be known, on one hand, subjectivism a rationalist, an empiricist objectivism another, it seems that, even with some attempts in advance before these extreme positions, did not emerge strongly and we have a world view sometimes curtailed by the rule of reason subjectivist, prays for the dictatorship of the empiricist objectivism. This dilemma seems to Edgy us of extremism, and skepticism, especially relativism. The sixteen Issue the First Part of the Summa Theologica, is inserted in the Treaty we call on God, and in this paper we explore the first article, in which Thomas discusses the truth is just the intellect and the sixth article that wonders if all things are true because of one truth or many. Given the discussions provoked in tomásico text and our considerations, we propose that a better understanding of truth occurs, in that we demonstrate a new paradigm and this is the paradigm of the relationship, so we believe it is important, both for epistemology, as anthropology to understand the truth as relative.

Keywords: Truth. Respect. Thomas Aquinas. Summa Theologica.

* Mestrando do Programa de Pós-graduação em Filosofia pela Universidade Federal de Maringá (UEM).

Bolsista CAPES. Contato: padrepaulinhoamaral@gmail.com

\begin{tabular}{|c|c|c|c|c|c|}
\hline intuitio & $\begin{array}{c}\text { ISSN } \\
1983-4012\end{array}$ & Porto Alegre & Vol.7 $-\mathrm{N}^{\mathrm{o} .2}$ & $\begin{array}{c}\text { Novembro } \\
2014\end{array}$ & p. 161-171 \\
\hline
\end{tabular}


A "verdade", enquanto relação, a partir da questão 16 da Primeira Parte da Suma Teológica de Tomás de Aquino

A Suma Teológica, magistral obra do teólogo e filósofo dominicano Tomás de Aquino (12241274), começou a ser escrita por ocasião de sua estadia em Roma em $1265^{1}$ e que o célebre pensador não conseguiu concluir, pois morre em 1274, deixando aos seus auxiliares o trabalho. Esta obra muito reconhecida no cenário acadêmico tanto da teologia como na filosofia, é composta de três grandes partes, cada parte se organiza em diversas questões e cada questão possui diversos artigos nos quais se debate teses buscando alcançar a verdade, é um método muito interessante aprimorado por Tomás ${ }^{2}$, buscando averiguar o que sabe sobre determinados temas e procurando avançar no conhecimento, a partir da discussão com as ideias até então propostas por diversas autoridades.

A Primeira parte da Suma trata de Deus em si mesmo e da criação dos anjos, das coisas materiais e do ser humano, é a menor das três, composta por 119 Questões. A Segunda parte é a maior, composta de 303 Questões organizadas em duas partes, 114 Questões na primeira parte da Segunda, e 189 Questões na segunda parte da Segunda, trata da moral, da finalidade da existência humana e a partir do ser humano, de todas as criaturas, e da Terceira Parte, “...Tomás redigiu apenas 90 questões, às quais seus secretários acrescentaram outras 99 ou 100, seguindo as indicações gerais do Mestre"3. Para a citação da Suma Teológica optamos por uma forma tradicional, a abreviatura ST (Suma Teológica), seguida pela parte (I, II ou III), pela Questão (Q. 16) e pelo Artigo e suas partes (Artigo 1).

Na Primeira Parte, com suas 119 Questões, que Tomás trata de Deus e de tudo o que não sendo Deus procede de Deus: as criaturas, anjos, coisas materiais e o ser humano; está inserida a Questão 16 que trata da verdade. Esta Primeira Parte, pode ser organizada em três partes: primeiro, discorrendo sobre a essência divina, da Questão segunda à Questão 26, depois sobre a distinção das pessoas, da Questão 27 à Questão 43 e numa terceira parte sobre a procedência das criaturas a partir de Deus, as Questões 44 a 119.

Buscamos refletir sobre a verdade, enquanto relação, nesta Questão 16 da Primeira da Suma, que está inserida no que chamamos Tratado sobre Deus, apenas a partir da Questão 75, temos o que denominamos Tratado sobre o ser humano, parece-nos já, nesta disposição metódica emergir no pensamento tomásico, o caráter relacional. O ser humano é intermediário no mundo criado, entre os anjos e as coisas materiais, Tomás apresenta o ser humano a partir da perspectiva bíblica semítica como imagem de Deus, “...segue a interpretação patrística dessa expressão e vê aí resumido o que caracteriza o ser humano: a inteligência e a vontade livre"”4.

Por isso entendemos que pesquisar sobre a verdade, enquanto relação, nos ajuda a aproximar a dimensão do conhecimento, propriamente humano, com a dimensão ontológica, o modo como a

\footnotetext{
${ }^{1}$ NASCIMENTO, Carlos Arthur Ribeiro. Um mestre no ofício: Tomás de Aquino. São Paulo: Paulus, 2011, p. 37.

${ }^{2} \mathrm{O}$ método das Disputas, ou seja, do debate das diversas teses conhecidas, ganha notoriedade com Pedro Abelardo(1079-1142), que o aprimora e o desenvolve, caracterizando-o assim como um dos principais métodos de exercício filosófico medieval, sobretudo a partir de sua adoção por Tomás de Aquino.

${ }^{3}$ NASCIMENTO, Carlos Arthur Ribeiro. Um mestre no ofício: Tomás de Aquino. São Paulo: Paulus, 2011, p. 75.

${ }^{4}$ NASCIMENTO, Carlos Arthur Ribeiro. Um mestre no ofício: Tomás de Aquino. São Paulo: Paulus, 2011, p. 76.
}

\begin{tabular}{|c|c|l|l|c|c|}
\hline intuitio & $\begin{array}{c}\text { ISSN } \\
1983-4012\end{array}$ & Porto Alegre & Vol.7- $\mathrm{N}^{\mathrm{o} .2}$ & $\begin{array}{c}\text { Novembro } \\
2014\end{array}$ & p. 161-171 \\
\hline
\end{tabular}


A "verdade", enquanto relação, a partir da questão 16 da Primeira Parte da Suma Teológica de Tomás de Aquino

realidade se apresenta ao ser humano dotado do instrumento da razão e da vontade, entendemos que esse modo se dá pela relação, não como um aspecto acidental ou secundário, mas essencial e determinante, o ser humano conhece na medida em que, inserido na realidade, coloca-se em relação com a mesma, a partir de si mesmo, dos objetos que o circunda e de sua capacidade de conhecer e desejar, visando a verdade e isso se dá de maneira relacional.

A Questão 16 da Primeira Parte da Suma é organizada em oito artigos e na introdução, Tomás afirma que, "Como o objeto da ciência é o verdadeiro, depois de considerar a ciência de Deus é preciso inquirir sobre a verdade" 5 , para com isso inquire se a verdade, encontra-se na coisa ou apenas no intelecto; se está no intelecto somente quando ele compõe e divide; como se dá o verdadeiro comparado com o ente e com o bem; se Deus é a verdade, se todas as coisas são verdadeiras em razão de uma única verdade ou de muitas; se a verdade é eterna e se é imutável.

Para demonstramos o caráter relacional da verdade, ainda que seja importante uma abordagem conjunta dos oito artigos da Questão 16, vamos ater-nos mais ao artigo primeiro que pergunta se a verdade se encontra na coisa, ou apenas no intelecto e ao artigo sexto que questiona se todas as coisas são verdadeiras em razão de uma única verdade ou de muitas.

A escolha destes dois artigos se deve ao fato de que, se a verdade se encontra apenas no intelecto ou apenas na coisa, não há interação, portanto não há relação e quanto ao artigo sexto se todas as coisas são verdadeiras em razão de uma única verdade ou de muitas verdades, seja em razão de uma única, seja em razão de muitas, há relação, e a verdade se dá justamente na medida e que as coisas são verdadeiras por causa de uma ou muitas verdades, portanto, são verdadeiras em relação a uma única ou a muitas verdades.

Esta inquietação quanto ao aspecto relacional da verdade aflora ainda mais no contexto de uma sociedade pluralista, multiculturalista e que seja do ponto de vista gnosiológico ou epistemológico, seja do ponto de vista antropológico, exige um aprofundamento das bases teóricas de um novo paradigma para uma convivência boa entre os seres humanos e dos seres humanos com todos os outros seres existentes que foram a realidade, o mundo em que estamos inseridos. Uma boa reflexão sobre o caráter relacional da verdade pode nos ajudar a enfrentar seja os relativismos, seja os ceticismos de nosso mundo hodierno e abrir caminho para uma ética dialógica e que nos ajude a retomar o compromisso de uma convivência o melhor possível entre todos, apesar de tantas diferenças, que na perspectiva relacional, somente expressam a complexidade e a grandeza da existência, especialmente da existência humana.

No primeiro artigo da Questão 16, Tomás pergunta: a verdade está apenas no intelecto? A tese colocada apresenta o seguinte problema: parece que a verdade não está apenas no intelecto, mas

\footnotetext{
5 AQUINO, Tomás de. Suma teológica. Vários tradutores. Coordenação Carlos Josaphat Pinto de Oliveira. São Paulo: Loyola, 2001-2006, Q.16.

\begin{tabular}{|c|c|c|c|c|c|}
\hline intuitio & $\begin{array}{c}\text { ISSN } \\
1983-4012\end{array}$ & Porto Alegre & Vol.7 $-\mathrm{N}^{\circ} .2$ & $\begin{array}{c}\text { Novembro } \\
2014\end{array}$ & p. 161-171 \\
\hline
\end{tabular}
}


A "verdade", enquanto relação, a partir da questão 16 da Primeira Parte da Suma Teológica de Tomás de Aquino principalmente nas coisas. ${ }^{6}$ Para realizar a disputada discussão, o Aquinate provoca um debate a partir das teses de Agostinho e Aristóteles. Em sua obra Solilóquios, Agostinho teria rejeitado esta definição da verdade: "o verdadeiro é o que se vê", cita o exemplo das pedras que se encontram na profundeza da terra, se fosse assim, não seriam pedras de verdade, porque não são vistas e, ainda Agostinho, rejeita a tese de que "o verdadeiro é o que aparece como tal, ao sujeito que conhece, se este quer e pode conhecê-lo", pois assim chegaríamos a um ceticismo, nada seria verdadeiro, se ninguém pudesse conhecê-lo e finalmente, apresenta a tese agostiniana: "o verdadeiro é o que é" ${ }^{7}$. Daí Tomás entende que, parece que a verdade está nas coisas e não no intelecto.

Num segundo momento, criticando os antigos filósofos quer diziam que "tudo o que parece é verdadeiro", Tomás reflete se, tudo o que é verdadeiro é verdadeiro pela verdade, sendo assim, se a verdade está unicamente no intelecto, nada será verdadeiro, a não ser enquanto se é conhecido, desse modo, mesmo as proposições contraditórias seriam simultaneamente verdadeiras, desde que parecessem a diversas pessoas simultaneamente verdadeiras. Parece-nos aqui, uma denúncia ao relativismo.

Buscando para a disputa o Filósofo Aristóteles, cita sua obra, Primeiros Analíticos, afirmando, "o que faz que uma coisa seja tal o é mais do que ela", e o livro das Categorias ao afirmar que, pelo fato de que uma coisa é ou não é, a opinião ou a palavra a ela referente será verdadeira ou falsa, então conclui que a verdade se encontra mais nas coisas do que no intelecto. ${ }^{8}$

No entanto, Tomás apresenta uma posição contrária, comum em sua discussão e disputa metódica, chamada "sed contra", para isso busca novamente Aristóteles que no livro VI da Metafisica diz que: "O verdadeiro e o falso não estão nas coisas, mas no intelecto"”.

Antes de averiguarmos a resposta de Tomás, que forma o corpo do artigo e a resposta a cada uma das objeções, observemos que, na apresentação do artigo, Tomás coloca o problema da verdade a partir da tese de que a verdade não está apenas no intelecto, "quod veritas non sit tantum in intellectu..."10 , o que nos faz refletir que podemos ter uma tese que defenda esta proposição de que a verdade esteja apenas no intelecto, seria a tese de Tomás? Seria a tese de outros pensadores? Mas a colocação do problema continua, e torna-se ainda mais pertinente, ao afirmar que é preciso inquirir; se a verdade não está apenas no intelecto, pois se afirma que, não está apenas no intelecto, mas

\footnotetext{
6 "Videtur quod veritas non sit tantum in intellectu, sed magis in rebus" (latim em itálico) (AQUINO, Tomás de. Suma teológica. Vários tradutores. Coordenação Carlos Josaphat Pinto de Oliveira. São Paulo: Loyola, 20012006, Art. 1).

7 "verum est id quod est" (AQUINO, Tomás de. Suma teológica. Vários tradutores. Coordenação Carlos Josaphat Pinto de Oliveira. São Paulo: Loyola, 2001-2006, Art. 1).

8 "Ergo veritas magis est in rebus quam in intellectu" (AQUINO, Tomás de. Suma teológica. Vários tradutores. Coordenação Carlos Josaphat Pinto de Oliveira. São Paulo: Loyola, 2001-2006, Art. 1).

${ }^{9}$ METAFÍSICA, C. 4: 1027, b, 25-29 In: AQUINO, Tomás de. Suma teológica. Vários tradutores. Coordenação Carlos Josaphat Pinto de Oliveira. São Paulo: Loyola, 2001-2006, Q 16, Art.1 sed contra.

${ }^{10}$ AQUINO, Tomás de. Suma teológica. Vários tradutores. Coordenação Carlos Josaphat Pinto de Oliveira. São Paulo: Loyola, 2001-2006, Q. 16. Art. 1, ao apresentar a tese a ser debatida assim expressa o Aquinate: "Quanto ao primeiro Artigo, assim se procede: parece que a verdade não está apenas no intelecto, mas principalmente nas coisas.". O negrito é nosso.

\begin{tabular}{|c|c|l|l|c|c|}
\hline intuitio & $\begin{array}{c}\text { ISSN } \\
1983-4012\end{array}$ & Porto Alegre & Vol.7- $\mathrm{N}^{\mathrm{o} .2}$ & $\begin{array}{c}\text { Novembro } \\
2014\end{array}$ & p. 161-171 \\
\hline
\end{tabular}
}


A "verdade", enquanto relação, a partir da questão 16 da Primeira Parte da Suma Teológica de Tomás de Aquino principalmente nas coisas, temos o lado, dos que defendem a tese de que, a verdade esteja principalmente nas coisas. Mas o que significa “a verdade não está apenas no intelecto?" e mais, o que significa, "mas principalmente nas coisas?", este "non sit tantum in intellectu"11 e "sed magis in rebus" ${ }^{12}$, coloca-nos diante das posições extremistas e reducionistas, de um lado, um subjetivismo, de outro, um objetivismo, o que pretendemos compreender a partir de Tomás é a possibilidade de avançar, superando tanto um como outro radicalismo, através de um paradigma que chamamos hipoteticamente "relacional".

Ao iniciar a resposta ao problema, Tomás introduz a questão do "tender" para, afirmando que “...chamamos bem àquilo a que tende o apetite, chamamos verdade àquilo a que tende o intelecto" 13 . Ao fazer esta abordagem a partir deste aspecto o do "tender" podemos outra vez identificar o aspecto relacional, seja no tocante a verdade mesma que é aquilo a que tende o intelecto, seja na relação entre o bem e a verdade, o apetite e o intelecto, estamos diante de elementos profundamente, senão essencialmente relacionais.

Mas, seguindo a resposta de Tomás, ele afirma que entre o apetite e o intelecto ou qualquer outra forma de conhecer há uma diferença:

O conhecimento consiste em que o conhecido está naquele que conhece, ao passo que a apetência consiste na inclinação do sujeito para aquilo que o atrai. Assim, o termo do apetite, que é o bem, se encontra na coisa que atrai, ao passo que o termo do conhecimento, a verdade, está no intelecto ${ }^{14}$.

Segundo Tomás, assim como o bem está na coisa, enquanto ordenada ao apetite, assim a razão da bondade passa da coisa que atrai ao apetite, por isso o apetite é bom, conforme é apetite do bem, da mesma forma o verdadeiro, estando no intelecto à medida que se conforma com a coisa conhecida, é necessário que a razão de verdadeiro passe do intelecto à coisa conhecida, assim a coisa conhecida é verdadeira, na medida que tem alguma relação com o intelecto. ${ }^{15}$

A tradução da Suma, que usamos para esta reflexão, coordenada pelo teólogo dominicano Carlos Josaphat de Oliveira, nos ajuda em nossa proposição e parece-nos corroborar com a mesma, o que conhecemos da realidade, a coisa conhecida é dita verdadeira na medida em que tem alguma relação com o intelecto, isso para nós é relevante, ainda que persistentemente complexo e problemático, mas aponta-nos um caminho capaz de nos ajudar avançar no processo do conhecimento

\footnotetext{
${ }^{11}$ AQUINO, Tomás de. Suma teológica. Vários tradutores. Coordenação Carlos Josaphat Pinto de Oliveira. São Paulo: Loyola, 2001-2006, Art. 1.

${ }^{12}$ AQUINO, Tomás de. Suma teológica. Vários tradutores. Coordenação Carlos Josaphat Pinto de Oliveira. São Paulo: Loyola, 2001-2006, Art. 1.

${ }^{13}$ AQUINO, Tomás de. Suma teológica. Vários tradutores. Coordenação Carlos Josaphat Pinto de Oliveira. São Paulo: Loyola, 2001-2006, Art. 1, resp.

${ }^{14}$ AQUINO, Tomás de. Suma teológica. Vários tradutores. Coordenação Carlos Josaphat Pinto de Oliveira. São Paulo: Loyola, 2001-2006, Art. I, resp.

${ }^{15}$ No original latino a expressão: “...a coisa é verdadeira na medida que tem alguma relação com o intelecto" é da seguinte forma "...ut res etiam intellecta vera dicatur, secundum quod habet aliquem ordinem ad intellectum" (AQUINO, Tomás de. Suma teológica. Vários tradutores. Coordenação Carlos Josaphat Pinto de Oliveira. São Paulo: Loyola, 2001-2006, Q.16, Art 1, resp.).

\begin{tabular}{|c|c|c|c|c|c|}
\hline intuitio & $\begin{array}{c}\text { ISSN } \\
1983-4012\end{array}$ & Porto Alegre & Vol.7- $\mathrm{N}^{\mathrm{o} .2}$ & $\begin{array}{c}\text { Novembro } \\
2014\end{array}$ & p. 161-171 \\
\hline
\end{tabular}
}


A "verdade", enquanto relação, a partir da questão 16 da Primeira Parte da Suma Teológica de Tomás de Aquino do ser humano, sobretudo suas potencialidades de relacionamentos, consigo próprio, com os outros seres humanos e com toda a realidade, a partir de sua capacidade intelectiva e volitiva, ambas reveladoras do caráter relacional, próprio no ser humano, mesmo sendo um ser intrinsecamente unitário, é composto, conforme Tomás, seguindo a literatura bíblica judaica e cristã e o hilemorfismo aristotélico.

Seguindo a resposta tomista, a coisa conhecida se refere ao intelecto por si ou por acidente, no original latino a expressão é "ordinem vel per se, vel per accidens" ${ }^{\prime 6}$, se refere por si ao intelecto quando depende do intelecto segundo seu ser e se refere ao intelecto por acidente na medida em que é cognoscível, então sentencia o Aquinate, “...o juízo sobre uma coisa não se faz em razão do que lhe é acidental, e sim do que lhe é essencial. Portanto uma coisa é verdadeira, absolutamente falando, segundo a relação com o intelecto de que depende." 17

A partir daí, são interessante os exemplos oferecidos por Tomás:

[...] uma casa é verdadeira quando se assemelha à forma que está na mente do artífice; uma frase é verdadeira quando é o sinal de um conhecimento intelectual verdadeiro. Assim também as coisas naturais são verdadeiras na medida em que se assemelham às representações que estão na mente divina: uma pedra é verdadeira quando tem a natureza própria da pedra, preconcebida como tal pelo intelecto divino $^{18}$.

Nestes exemplos emerge um importante conceito do pensamento tomásico, a noção de "similitude", as coisas são verdadeiras quando se assemelham, "...quae assequitur similitudinem formae quae est in mente artificis..." é possível estabelecer uma similitude entre uma coisa e outra se antes for possível estabelecer uma relação, a relação é condição necessária para que se estabeleça uma semelhança, até por isso afirmamos "uma relação de semelhança".

Então conclui Tomás em sua resposta, "a verdade está principalmente no intelecto, secundariamente nas coisas, na medida em que se referem ao intelecto, como a seu princípio". ${ }^{20}$ Parece-nos muito contundente o argumento para sustentar nossa tese, de que a verdade, não está no intelecto ou nas coisas, é o próprio Tomás que afirma, a verdade está principalmente no intelecto, não simples ou totalmente no intelecto, não temos um subjetivismo ou intelectualismo, a verdade que está principalmente no intelecto está ainda que, secundariamente nas coisas, mesmo que esteja na medida em que se referem ao intelecto, como a seu princípio, o fato de estar secundariamente nas coisas e

\footnotetext{
${ }^{16}$ AQUINO, Tomás de. Suma teológica. Vários tradutores. Coordenação Carlos Josaphat Pinto de Oliveira. São Paulo: Loyola, 2001-2006, Q. 16. Art. 1, resp.

${ }^{17}$ AQUINO, Tomás de. Suma teológica. Vários tradutores. Coordenação Carlos Josaphat Pinto de Oliveira. São Paulo: Loyola, 2001-2006, Q. 16, Art. 1, resp.

${ }^{18}$ AQUINO, Tomás de. Suma teológica. Vários tradutores. Coordenação Carlos Josaphat Pinto de Oliveira. São Paulo: Loyola, 2001-2006, Q. 16, Art. 1, resp.

${ }^{19}$ AQUINO, Tomás de. Suma teológica. Vários tradutores. Coordenação Carlos Josaphat Pinto de Oliveira. São Paulo: Loyola, 2001-2006, Q. 16. Art. 1, resp.

${ }^{20}$ AQUINO, Tomás de. Suma teológica. Vários tradutores. Coordenação Carlos Josaphat Pinto de Oliveira. São Paulo: Loyola, 2001-2006, Q. 16, art. 1, resp.

\begin{tabular}{|c|c|c|c|c|c|}
\hline intuitio & $\begin{array}{c}\text { ISSN } \\
1983-4012\end{array}$ & Porto Alegre & Vol.7- $\mathrm{N}^{\mathrm{o} .2}$ & $\begin{array}{c}\text { Novembro } \\
2014\end{array}$ & p. 161-171 \\
\hline
\end{tabular}
}


A "verdade", enquanto relação, a partir da questão 16 da Primeira Parte da Suma Teológica de Tomás de Aquino referindo-se ao intelecto como seu principio, demonstra o caráter relacional da verdade. Nem subjetivismo, nem objetivismo, mas a verdade que se dá a partir de uma dinâmica relacional, produzida no intelecto, e através da relação entre o intelecto e as coisas.

Por causa dessas considerações é que, segundo Tomás, a verdade é definida diversamente, cita Agostinho que define a verdade como "aquilo pelo qual é manifestado o que é" ${ }^{21}$, em sua obra $D a$ verdadeira Religião, Santo Hilário ao dizer que, "o verdadeiro é a declaração ou a manifestação do ser",22, aqui teríamos a verdade enquanto no intelecto e quanto à verdade da coisa enquanto ordenada ao intelecto, cita novamente Agostinho que define a verdade como "...a perfeita semelhança com o principio, sem nenhuma dessemelhança" 23 e, Anselmo afirmando que, "a verdade é a retidão que só a mente percebe" ${ }^{24}$. E, ainda recorda Avicena, afirmando que "a verdade de cada coisa consiste na propriedade do seu ser que lhe foi conferido" ${ }^{25}$, finalmente cita a clássica definição de verdade como “...adequação da coisa e do intelecto" ${ }^{26}$ e que segundo Tomás pode se referir tanto quanto a verdade no intelecto, quanto à verdade da coisa enquanto ordenada ao intelecto e diz isso concluindo que se trata de aspectos da verdade, o que outra vez nos parece corroborar como defensável, o aspecto relacional da verdade.

Na última parte do artigo primeiro desta Questão 16, em que Tomás especula, se a verdade está apenas no intelecto e ao apresentar as objeções à tese colocada, em que se afirma parecer que a verdade não está apenas no intelecto, mas principalmente nas coisas, o Aquinate responde a cada uma das três objeções, a de Santo Agostinho, a dos filósofos antigos e a de Aristóteles.

Na resposta à objeção agostiniana, Tomás afirma que Agostinho fala da verdade da coisa, excluindo da razão desta verdade a relação com nosso intelecto, portanto, afirma que há na razão da verdade uma relação com nosso intelecto, mas Tomás entende que é acidental, “...pois o que é acidental exclui-se de qualquer definição". ${ }^{27}$

A questão se torna ainda mais interessante quando responde aos filósofos antigos, pois segundo Tomás, estes não faziam proceder as espécies das coisas naturais de um intelecto, mas do acaso e que "[...]como consideravam que o verdadeiro implica uma relação com o intelecto, viam-se obrigados a estabelecer a verdade das coisas em sua relação com o intelecto" ${ }^{28}$. Para Tomás, por isso

\footnotetext{
${ }^{21}$ Agostinho, Da verdadeira religião. In: AQUINO, Tomás de. Suma teológica. Vários tradutores. Coordenação Carlos Josaphat Pinto de Oliveira. São Paulo: Loyola, 2001-2006, Q. 16. Art. 1, resp.

${ }^{22}$ ST I, Q. 16. Art. 1, resp.

${ }^{23}$ Agostinho, Da verdadeira religião. In: AQUINO, Tomás de. Suma teológica. Vários tradutores. Coordenação Carlos Josaphat Pinto de Oliveira. São Paulo: Loyola, 2001-2006, Q. 16. Art. 1, resp.

${ }^{24}$ Anselmo, Santo. Diálogo De veritatis. In: AQUINO, Tomás de. Suma teológica. Vários tradutores. Coordenação Carlos Josaphat Pinto de Oliveira. São Paulo: Loyola, 2001-2006, Q. 16. Art. 1, resp.

${ }^{25}$ Avicena, Metaphisica. In: AQUINO, Tomás de. Suma teológica. Vários tradutores. Coordenação Carlos Josaphat Pinto de Oliveira. São Paulo: Loyola, 2001-2006, Q. 16. Art. 1, resp.

${ }^{26}$ AQUINO, Tomás de. Suma teológica. Vários tradutores. Coordenação Carlos Josaphat Pinto de Oliveira. São Paulo: Loyola, 2001-2006, Q. 16. Art. 1, resp.

${ }^{27}$ AQUINO, Tomás de. Suma teológica. Vários tradutores. Coordenação Carlos Josaphat Pinto de Oliveira. São Paulo: Loyola, 2001-2006, Q. 16, a.1, resp. 1'a objeção.

${ }^{28}$ AQUINO, Tomás de. Suma teológica. Vários tradutores. Coordenação Carlos Josaphat Pinto de Oliveira. São Paulo: Loyola, 2001-2006, Q. 16, art. 1, resp. 2a. objeção.

\begin{tabular}{|c|c|c|c|c|c|}
\hline intuitio & $\begin{array}{c}\text { ISSN } \\
1983-4012\end{array}$ & Porto Alegre & Vol.7- N $^{\circ} .2$ & $\begin{array}{c}\text { Novembro } \\
2014\end{array}$ & p. 161-171 \\
\hline
\end{tabular}
}


A "verdade", enquanto relação, a partir da questão 16 da Primeira Parte da Suma Teológica de Tomás de Aquino

Aristóteles no livro IV da Metafísica apresenta diversos erros e inconvenientes desta visão e afirma Tomás, optando por um paradigma relacional que, "esses inconvenientes, porém, não acontecem se fazemos consistir a verdade das coisas na relação com o intelecto divino" ${ }^{2930}$ (atenção! Cancelar a nota 28 , basta a 29 com a referencia no final). Portanto, precisamos admitir o aspecto relacional na consecução da verdade, ainda que seja acidental, no caso da relação das coisas e o intelecto humano, mas essencial quando se trata da verdade das coisas na relação com o intelecto divino. É esse aspecto que temos destacado, e que nos parece ter ficado ofuscado, tanto na concepção gnosiológica, quanto antropológica, do pensamento tomásico, o que para nós, traz sérias consequências, sobretudo para a ética.

Na resposta à terceira objeção, diz Tomás, “...ainda que a verdade de nosso intelecto seja causada pela coisa, não se segue que a razão da verdade se encontre primeiro na coisa, assim como a razão da saúde não se encontra primeiro no remédio e sim no animal”31. A partir desta resposta, conseguimos demonstrar com vigor, a importância da relação entre a coisa e o intelecto, ainda que a razão da verdade não se encontre primeiro na coisa, deve encontrar também na coisa, mesmo que secundariamente, e a verdade se dá justamente na medida em que se estabelece essa relação entre o intelecto e a coisa, não que a relação seja a verdade, entendemos que a relação torna possível a apreensão da verdade. Mas é preciso que estejamos atentos ainda ao que afirma Tomás, “...é o ser da coisa, e não sua verdade, que causa a verdade no intelecto"32. Estamos diante de um pensamento fundante da visão tomásica da verdade, para que algo seja conhecido e conhecido como verdadeiro é necessário que antes, seja, por isso entendemos que todo o processo do conhecimento e ousaríamos afirmar da existência e, especialmente da existência humana é "relacional", o ser humano, dotado de razão e vontade, descobre-se no mundo e coloca-se em relação com o mundo e entendemos que isso se dá de uma forma triádica e profundamente relacional: ser-verdade-conhecer.

Concluindo a resposta à terceira objeção, Tomás cita o próprio Aristóteles quando diz que uma opinião ou uma palavra é verdadeira porque a coisa é, e não porque a coisa é verdadeira. A partir da abordagem que estamos propondo, afirmaríamos que uma opinião ou uma palavra é verdadeira porque a coisa é e estabelece no intelecto humano uma relação com a sua verdade e com a verdade. Não temos aqui nem relativismo, nem ceticismo, mas um paradigma relacional para a noção de verdade.

No artigo seis, desta Questão 16, a pergunta é, se todas as coisas são verdadeiras em razão de uma única verdade? A tese colocada é que parece que há uma única verdade em razão da qual todas as coisas são verdadeiras.

\footnotetext{
${ }^{29}$ AQUINO, Tomás de. Suma teológica. Vários tradutores. Coordenação Carlos Josaphat Pinto de Oliveira. São Paulo: Loyola, 2001-2006, Q. 16, art. 1, resp. 2a . objeção.

30 "...Quae quidem inconvenientia non accident, si ponamus veritatem rerum consistere in comparatione ad intellectum divinum" in: ST I, Q. 16, art. 1, resp. $2^{\mathrm{a}}$. objeção.

${ }^{31}$ AQUINO, Tomás de. Suma teológica. Vários tradutores. Coordenação Carlos Josaphat Pinto de Oliveira. São Paulo: Loyola, 2001-2006, Q. 16, art. 1, resp. 3ª objeção.

${ }^{32}$ AQUINO, Tomás de. Suma teológica. Vários tradutores. Coordenação Carlos Josaphat Pinto de Oliveira. São Paulo: Loyola, 2001-2006, Q. 16, art. 1, resp. 3ª objeção.

\begin{tabular}{|c|c|c|c|c|c|}
\hline intuitio & $\begin{array}{c}\text { ISSN } \\
1983-4012\end{array}$ & Porto Alegre & Vol.7- N $^{\circ} .2$ & $\begin{array}{c}\text { Novembro } \\
2014\end{array}$ & p. 161-171 \\
\hline
\end{tabular}
}


A "verdade", enquanto relação, a partir da questão 16 da Primeira Parte da Suma Teológica de Tomás de Aquino

Neste artigo, Tomás apresenta a autoridade de Agostinho e Anselmo para debater esta questão. Primeiro, segundo Agostinho, “"nada é maior do que a mente humana, exceto Deus"”,33 e reflete Tomás que a verdade é maior que a mente humana, pois a mente humana julga segundo a verdade e não segundo a si mesma, então, somente Deus é a verdade, não deve haver outra verdade, senão Deus. Seguindo, Tomás apresenta o argumento tirado de Anselmo ${ }^{34}$ em sua obra Sobre a Verdade, que diz que a verdade se refere às coisas verdadeiras como o tempo às coisas temporais, se existe apenas um tempo de todas as coisas temporais, deve existir apenas uma verdade pela qual tudo é verdadeiro ${ }^{35}$. Mas Tomás apresenta então uma tese contraditória, buscada na autoridade das Escrituras Sagradas, apresenta um versículo do salmo bíblico 11 afirmando que "as verdades desapareceram dos filhos dos homens" ${ }^{\prime 36}$.

A resposta tomásica a estas objeções demonstram a envergadura de nossa proposição da verdade, enquanto relação. Afirma, "em certo sentido, em outro não, existe uma única verdade pela qual tudo é verdadeiro" ${ }^{\text {37 }}$. Tomás retoma a sua tese de que a verdade se encontra primeiro no intelecto, e posteriormente nas coisas, na medida em que estas se referem ao intelecto divino, 'secundum quod ordinantur ad intellectum divinum ${ }^{38}$.

Quando falamos da verdade enquanto está no intelecto segundo a sua própria razão, então existem em intelectos criados muitas verdades e, também no mesmo intelecto, segundo a variedade de coisas conhecidas, de uma mesma verdade divina resultam várias verdades, mas quando falamos da verdade enquanto está na coisa, todas as coisas são verdadeiras em razão de uma única e primeira verdade, a que cada uma é assemelhada segundo seu modo de ser, mesmo que existam muitas essências ou formas das coisas, a verdade do intelecto divino é única, e por esta verdade única todas as coisas são denominadas verdades. Mas aqui fixamos nossa atenção no que afirmara anteriormente Tomás, existem nos intelectos criados muitas verdades, por isso, a verdade buscada e encontra pelo intelecto humano é relacional.

Concluindo nossa reflexão, apresentamos a reflexão de Tomás nas Questões Disputadas sobre a Verdade, a Primeira Questão especula sobre a verdade em doze artigos, propomos apenas a solução dada por Tomás ao artigo quarto que inquire se há somente uma verdade pela qual todas as coisas são verdadeiras.

\footnotetext{
33 Agostinho, De Trinit., lib XV, c. 1: ML 42, 1044, 1058. In: AQUINO, Tomás de. Suma teológica. Vários tradutores. Coordenação Carlos Josaphat Pinto de Oliveira. São Paulo: Loyola, 2001-2006, Q. 16, a. 6.

34 Anselmo (1033-1109), monge beneditino e filósofo medieval, famoso por seu argumento sobre o conhecimento da existência de Deus, chamado por Kant, "argumento ontológico".

${ }^{35}$ Anselmo, Santo. De veritate, c. 14. In: AQUINO, Tomás de. Suma teológica. Vários tradutores. Coordenação Carlos Josaphat Pinto de Oliveira. São Paulo: Loyola, 2001-2006, Q. 16. Art. 6, resp.

${ }^{36}$ Salmo 11,2

${ }^{37}$ AQUINO, Tomás de. Suma teológica. Vários tradutores. Coordenação Carlos Josaphat Pinto de Oliveira. São Paulo: Loyola, 2001-2006, Q. 16, art. 16, resp.

${ }^{38}$ AQUINO, Tomás de. Suma teológica. Vários tradutores. Coordenação Carlos Josaphat Pinto de Oliveira. São Paulo: Loyola, 2001-2006, Q. 16. Art. 6, resp.

\begin{tabular}{|c|c|c|c|c|c|}
\hline intuitio & $\begin{array}{c}\text { ISSN } \\
1983-4012\end{array}$ & Porto Alegre & Vol.7 $-\mathrm{N}^{\circ} .2$ & $\begin{array}{c}\text { Novembro } \\
2014\end{array}$ & p. 161-171 \\
\hline
\end{tabular}
}


A "verdade", enquanto relação, a partir da questão 16 da Primeira Parte da Suma Teológica de Tomás de Aquino

Na resposta Tomás explica que a verdade encontra-se propriamente no intelecto humano ou divino, como a saúde no animal; nas outras coisas, porém a verdade encontra-se pela relação ao intelecto $^{39}$, assim encontramos no próprio texto tomásico, o conceito "pela relação", traduzido do original latino "per relationem". E segue o Aquinate:

Portanto a verdade está primeira e propriamente no intelecto divino; própria, mas secundariamente no intelecto humano; nas coisas, todavia, imprópria e secundariamente, porquanto se encontra somente por relação a uma das duas verdades. Portanto a verdade do intelecto divino é uma apenas, desta derivam no intelecto humano muitas verdades, 'como de um único semblante do homem resultam muitos símiles no espelho ${ }^{40}$.

Para Tomás, a verdade das coisas em comparação com o intelecto humano é de certa forma acidental às próprias coisas, se o intelecto humano não existisse, as coisas permaneceriam em sua essência, cada coisa é verdadeira primeiramente em relação ao intelecto divino, aqui o original latino é “in ordine ad veritatem intellectus divini”"11 e depois em relação à verdade do intelecto humano.

O que pretendemos demonstrar é que, uma noção de verdade enquanto relação, ou a partir do paradigma da relação, contribui para que superemos o subjetivismo racionalista, que fecha o ser humano em sua própria razão, e faz emergir um complexo problema: como o ser humano pensante, coloca-se diante do mundo objetivante, e de outro lado, o objetivismo que reduz a realidade ao objeto, fechando-o em si mesmo da mesma forma. Assim, se compreendemos a verdade enquanto relação, podemos concluir pela complexa riqueza que a possibilidade do conhecimento nos dá, não a partir de um ser arrogante e que coloca como capaz de criar a realidade, nem a partir de uma realidade opressora, massacrante, que dilua o ser humano, capaz de pensar e amar, inviabilizando justamente o exercício destas características diferenciais, mas a parir de um ser humano, dotado de inteligência e vontade e que, por isso, coloca-se em relação diante do outro, seja o outro ser humano, seja as outras coisas presentes no mundo e até mesmo o Outro.

O paradigma da relação, na compreensão da verdade, pode nos ajudar na superação de radicalismos e fanatismos, terrorismos e falta de sentido para uma existência humana indecifrável e sem finalidade, que tanto hoje nos preocupa; a partir da formatação de uma estrutura teórica, que sustente uma prática dialógica e relacional, uma filosofia que ajude a compreender as diferenças, a partir da concepção da verdade, enquanto relação.

\footnotetext{
39 "In rebus autem aliis invenitur veritas per relationem ad intellectum..." In: Questões disputadas sobre a Verdade, Primeira Questão, Artigo 4, resp.

${ }^{40}$ AQUINO, Tomás de. Verdade e conhecimento. In: Questões disputadas sobre a Verdade. Trad., estudos introdutórios e notas de Luiz Jean Lauand, e Mario Bruno Sproviero. 2. ed. São Paulo: Editora WMF Martins Fontes, 2011. Primeira Questão, Artigo 4, resp. p. 181-182.

${ }^{41}$ ST I, Q. 16. Art. 1, resp.

\begin{tabular}{|c|c|l|l|c|c|}
\hline intuitio & $\begin{array}{c}\text { ISSN } \\
1983-4012\end{array}$ & Porto Alegre & Vol.7- $\mathrm{N}^{\mathrm{o} .2}$ & $\begin{array}{c}\text { Novembro } \\
2014\end{array}$ & p. 161-171 \\
\hline
\end{tabular}
}


A "verdade", enquanto relação, a partir da questão 16 da Primeira Parte da Suma Teológica de Tomás de Aquino

\section{Referências}

AQUINO, Tomás de. Suma teológica. Vários tradutores. Coordenação Carlos Josaphat Pinto de Oliveira. São Paulo: Loyola, 2001-2006, 9 vols.

. Verdade e conhecimento. In: Questões disputadas sobre a Verdade. Trad, estudos introdutórios e notas de Luiz Jean Lauand e Mario Bruno Sproviero. 2. ed. São Paulo: Editora WMF Martins Fontes, 2011.

NASCIMENTO, Carlos Arthur Ribeiro. Um mestre no ofício: Tomás de Aquino. São Paulo: Paulus, 2011.

Recebido em: 31/05/2014

Aprovado para publicação em: 16/09/2014 